transforming ethane into $\mathrm{CO}_{2}$ ? Chen and colleagues demonstrate unambiguously that the genome of $\mathrm{Ca}$. A. ethanivorans contains three genes that encode the subunits of a previously unknown enzyme, which we call here ethyl-coenzyme $\mathrm{M}$ reductase (ECR). They then identify the protein sequence of ECR using mass spectrometry. ECR is closely related to an enzyme called methyl-coenzyme $\mathrm{M}$ reductase (MCR), which is present in microorganisms that oxidize or generate methane. Chen et al. also identify the final product of the reaction catalysed by ECR, ethyl-coenzyme M.

Chen et al. modelled the 3D structures of the Ca. A. ethanivorans ECR and the butane-metabolizing enzyme (butylcoenzyme M reductase) of 'Candidatus Syntrophoarchaeum, ${ }^{4}$, and compared them with the known structure of the MCR of Methanothermobacter marburgensis ${ }^{7}$. On the basis of this structure comparison, as well as an alignment of the sequences of all known MCRrelated proteins, they conclude that ECR and the other enzymes that metabolize non-methane hydrocarbon gases form a distinct cluster within an overarching group of enzymes called the alkyl-coenzyme M reductase (ACR) family, which catalyse the anaerobic oxidation of alkanes.

By analogy with the well-studied enzymatic mechanism of $\mathrm{MCR}^{8}$, it is likely that ECR initiates anaerobic ethane oxidation by transforming ethane into an ethyl radical molecule, which is very reactive. It will be exciting when researchers are able to generate sufficient amounts of ECR to determine its enzymatic and biophysical properties. For example, how does it selectively catalyse the oxidation of ethane when the natural gas plumes where $\mathrm{Ca}$. A. ethanivorans grows are so rich in methane? The authors' analysis did not reveal any obvious distinguishing features of the binding pockets of ACR enzymes, including ECR, that could explain their preference for metabolizing specific alkanes. However, the structures that the authors compared represent the inactive states of ACRs. It is to be hoped that the crystal structures of the active states of this enzyme family will soon be determined to help clarify this and other questions about their mechanism.

Chen et al. propose a plausible route from ECR-generated ethyl-coenzyme $\mathrm{M}$ to $\mathrm{CO}_{2}$. In this model, ethyl-coenzyme $\mathrm{M}$ is transformed into acetyl-coenzyme A, a molecule involved in many other metabolic processes, which is then oxidized through a mechanism called the reverse Wood-Ljungdahl pathway ${ }^{9}$. The authors identified proteins that are involved in this pathway using genomic and proteomic methods. However, the conversion of ethyl-coenzyme $\mathrm{M}$ to acetyl-coenzyme A still requires experimental validation. A similar gap in knowledge also exists for other non-methane oxidation pathways, including anaerobic butane oxidation by $\mathrm{Ca}$. Syntrophoarchaeum ${ }^{4}$.

The next logical steps are to resolve the controversy regarding the nature of the communication between the newly identified ethane-oxidizing microorganism and its sulfate-reducing partner, and to build the metabolic bridge between ethyl-coenzyme $\mathrm{M}$ and acetyl-coenzyme A.

Stephen W. Ragsdale is in the Department of Biological Chemistry, University of Michigan Medical School, Ann Arbor, Michigan

48109-0606, USA.

e-mail:sragsdal@umich.edu

1. Judd, A. G. Environ. Geol. 46, 988-996 (2004).

2. Chen, S.-C. et al. Nature 568, 108-111

(2019).
3. Krukenberg, V. et al. Environ. Microbiol. 20, 1651-1666 (2018).

4. Laso-Pérez, R. et al. Nature 539, 396-401 (2016)

5. McGlynn, S. E., Chadwick, G. L., Kempes, C. P. \& Orphan, V. J. Nature 526, 531-535 (2015).

6. Milucka, J. et al. Nature 491, 541-546 (2012).

7. Ermler, U., Grabarse, W., Shima, S., Goubeaud, M. \& Thauer, R. K. Science 278, 1457-1462 (1997)

8. Wongnate, T. et al. Science 352, 953-958 (2016).

9. Ragsdale, S. W. \& Pierce, E. Biochim. Biophys. Acta 1784, 1873-1898 (2008).

10.Plass-Dülmer, C., Koppmann, R., Ratte, M. \& Rudolph, J. Glob. Biogeochem. Cycles 9, 79-100 (1995).

11.Etiope, G. \& Ciccioli, P Science 323, 478 (2009)

12.Bousquet, P. et al. Nature 443, 439-443 (2006).

13.Dalsøren, S. B. et al. Nature Geosci. 11, 178-184 (2018).

This article was published online on 27 March 2019.

\title{
ECOLOGY
}

\section{Coral symbiosis is a three-player game}

\begin{abstract}
DNA analysis and microscopy reveal a third organism in the symbiosis that forms coral. The finding underscores the functional and evolutionary complexity of the symbiotic relationships that support many ecosystems. SEE LETTER P.103
\end{abstract}

\section{THOMAS A. RICHARDS \\ \& JOHN P. MCCUTCHEON}

0 ymbiosis is deceptively easy to define: two or more organisms live together in a longterm association. Coral, the partnership between an animal from the Anthozoa group and a microbial alga called Symbiodinium, is an archetypal model of symbiosis. The anthozoan provides a home for the alga, which uses photosynthesis to produce sugars that are

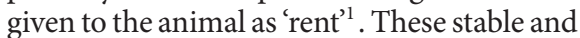
highly productive two-player symbioses build the enormous reefs that shape marine ecosystems. On page 103, Kwong et al. ${ }^{2}$ challenge this simple binary model of coral symbiosis by identifying a third player in the association.

Microorganisms, by definition, are tiny, and as such are difficult to isolate, grow and study. The vast extent of microbial diversity has been recognized only in the past two decades, after the application of molecular-biology techniques to the field ${ }^{3}$. The majority of newly discovered microbial groups are cryptic lineages that greatly outnumber the 'known' diversity of life ${ }^{4}$, and are recognized only as DNA sequences stored in databases. We know little about what these microbes look like, how their cells function or what they do in an ecosystem. The challenge, therefore, is to map the DNA sequences that identify these microbes to physical cells, and to uncover the biology of such organisms. This is not an easy task.

Two such types of mystery DNA sequence, called ARL-V (apicomplexan-related lineage- $\mathrm{V}$ ) and type- $\mathrm{N}$, have been consistently

found in samples from coral ecosystems ${ }^{5}$. Phylogenetic trees that map how the organisms containing ARL-V and type-N DNA are related to known microbes suggest that these organisms belong to the Apicomplexa. This group includes parasites that infect terrestrial animals, such as the Plasmodium species that cause malaria, so understanding more about the provenance and evolution of the microbes these sequences represent is of broad interest.

Many apicomplexan parasites live in the dark, but they contain the vestige of a plas$\operatorname{tid}^{6}$, a DNA-containing structure found in plant and algal cells

"The challenge now is to identify the role of the extraparties in corals, lichens and many other symbioses." that is required for photosynthesis. The evolutionary origin of plastids in the Apicomplexa is poorly understood. Apicomplexan plastids are non-photosynthetic, but they have retained some biochemical pathways that are found alongside the light-processing pathways in photosynthetic plastids. Many of these pathways are potential targets of antimalarial drugs. Photosynthetic relatives of the Apicomplexa have also been discovered in marine environments ${ }^{7}$. But how do the elusive microbes that contain ARL-V and type-N DNA fit into this picture, and what can they tell us about coral ecosystems and the evolutionary history of the Apicomplexa?

Kwong and colleagues were intrigued by the apparent association of the 

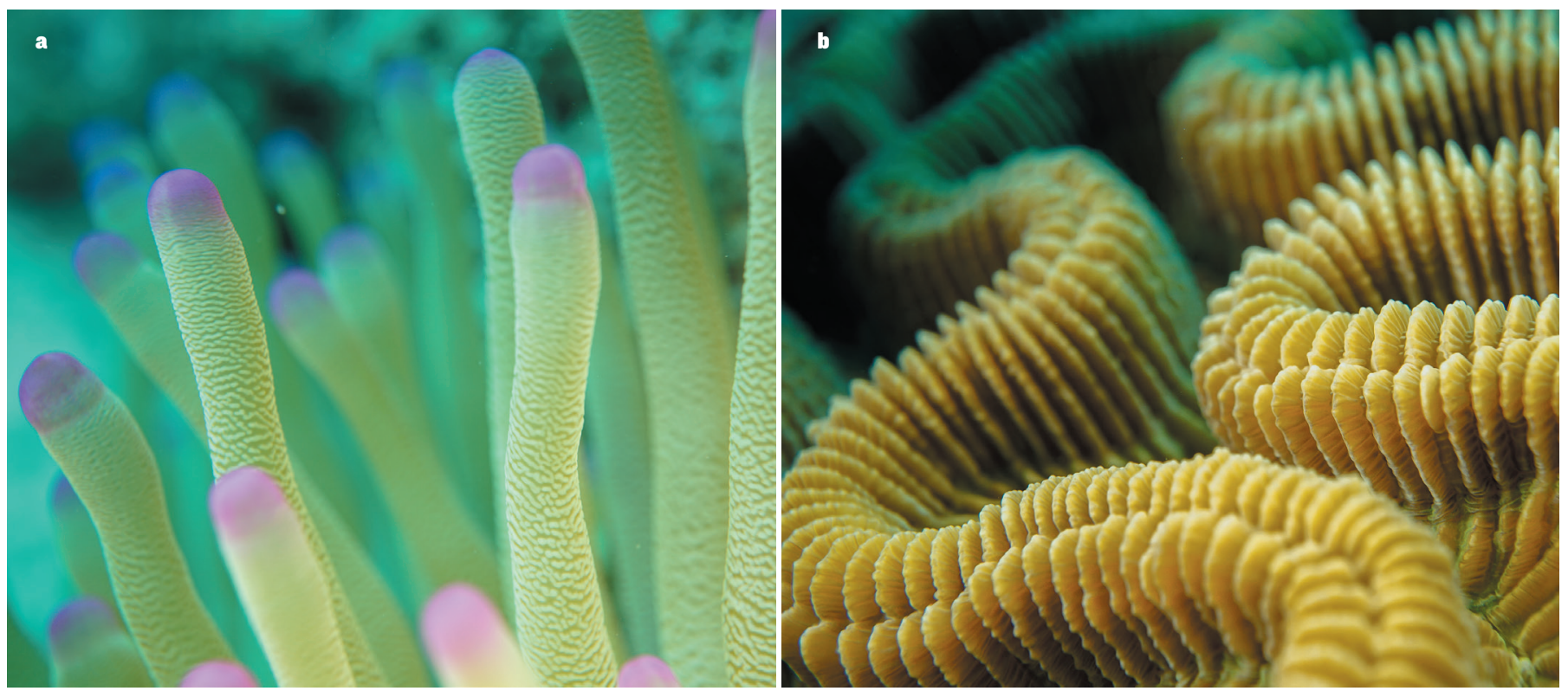

Figure 1 | Different biological groups are hosts to corallicolids. Kwong et al. ${ }^{2}$ identified microorganisms belonging to the Apicomplexa group in many related symbiotic associations, such as anemones (a) and corals (b). The authors named these microorganisms corallicolids. (Images courtesy of P. J. Keeling.)

ARL-V/type-N DNA signature with corals and related species (Fig. 1). They screened DNA samples from 62 wild and aquarium species for the presence of type- $\mathrm{N}$ signatures, and found that $70 \%$ of the species were type-N-positive. Using fluorescently labelled DNA probes, Kwong and colleagues then observed that type-N and ARL-V DNA molecules coexist in cells located inside the gastric cavity cells of the anthozoans. This pattern of localization of ARL-V/type- $\mathrm{N}$ cells in the coral is distinct from that of Symbiodinium algae, indicating that the newly identified symbionts participate in an anatomically separate interaction with the anthozoan animal. Electron microscopy showed that the ARL-V/type-N cells have many features typical of apicomplexan cells. The authors informally named the organisms 'corallicolids'.

Kwong et al. then used several genetic markers to investigate the position of corallicolids in the tree of life. This revealed a peculiar evolutionary placement: corallicolids are more closely related to terrestrial than to previously identified marine Apicomplexa. This finding inspired the authors to sequence the full genome of the corallicolids' plastid, which led to another surprise. The corallicolids have retained genes encoding molecules that synthesize chlorophyll, the pigment that absorbs energy from light to enable photosynthesis. However, they have lost the plastid genes that encode the proteins of photosystems, which carry out photosynthesis.

How might corallicolids avoid the toxic chemical effects resulting from the excitation of chlorophyll by light when they lack the normal outlet of a photosystem? There are two possible explanations, both intriguingly unlikely. In contrast to the situation in all known photosynthetic eukaryotes (species that carry their
DNA in a nucleus), the genes that encode the photosystem proteins in corallicolids might be part of the nuclear genome, instead of being part of the plastid genome. After synthesis, these proteins would be transported into the plastid. Alternatively, corallicolids might have unique biochemical pathways involving chlorophyll that are not associated with photosystems.

The term symbiosis is often used synonymously with mutualism, a relationship in which all partners benefit. This is a misapplication of the term that obscures much of the dynamic nature of these interactions ${ }^{8}$. The report by Kwong and colleagues is not the first case in which a classic model of twoplayer mutualistic symbiosis has turned out to be more complex than originally described. Many lichens - another archetypal model of symbiosis - are composed not of just one fungus and one alga, but of three or four evolutionarily stable partners ${ }^{9,10}$.

Why are additional symbionts present in these associations? We suspect the answer relates to the nutritional nature of the symbioses. In both corals and lichens, an organism synthesizes carbon compounds and leaks them to another organism in exchange for housing and other benefits. It seems unsurprising that further organisms might exploit either the leaked compounds or the willingness of a larger organism to house a smaller organism. In the process of exploitation, these new players might bring a new beneficial function to the symbiosis.

The challenge now is to identify the role of the extra parties in corals, lichens and many other symbioses, and to rethink the roles of the better-known partners in light of the new evidence. Do the additional players cause disease in the symbiosis? A formal test of Koch's postulates $^{11}$, which establish a causal link between a microbe and a disease, requires cell cultures. These are unavailable for corallicolids and most lichen-associated fungi, so a potential link with disease is difficult to determine. Do the new players provide some important nutritional ${ }^{12}$ or protective service for the symbiosis? Do they perform policing functions, ensuring community stability?

We would not be surprised if many of the additional players identified in these symbioses had multiple and dynamic roles. Solving this riddle will be a challenge, but it should tell us a lot about how organisms perceive each other and interact in complex social contexts, and what kinds of interaction ultimately build the symbioses on which many ecosystems rely.

Thomas A. Richards is in Biosciences, Living Systems Institute, University of Exeter, Exeter EX4 4QD, UK. John P. McCutcheon is in the Division of Biological Sciences, University of Montana, Missoula, Montana 59812, USA.

e-mails: t.a.richards@exeter.ac.uk; john.mccutcheon@umontana.edu

1. Baker, A. C. Annu. Rev. Ecol. Evol. Syst. 34, 661-689 (2003).

2. Kwong, W. K., del Campo, J., Mathur, V., Vermeij, M. J. A. \& Keeling, P. J. Nature 568, 103-107 (2019).

3. Pace, N. R. Science 276, 734-740 (1997).

4. Hug, L. A. et al. Nature Microbiol. 1, 16048 (2016).

5. Janouškovec, J., Horák, A., Barott, K. L., Rohwer, F. L. \& Keeling, P. J. Curr. Biol. 22, R518-R519 (2012)

6. McFadden, G. I., Reith, M. E., Munholland, J. \& Lang-Unnasch, N. Nature 381, 482 (1996).

7. Moore, R. B. et al. Nature 451, 959-963 (2008).

8. Wooldridge, S. A. BioEssays 32, 615-625 (2010).

9. Spribille, T. et al. Science 353, 488-492 (2016).

10.Tuovinen, V. et al. Curr. Biol. 29, 476-483 (2019).

11.Fredericks, D. N. \& Relman, D. A. Clin. Microbiol. Rev. 9, 18-33 (1996).

12.Lesser, M. P., Mazel, C. H., Gorbunov, M. Y. \& Falkowski, P. G. Science 305, 997-1000 (2004). 